\title{
IMPLEMENTASI KEBIJAKAN PROGRAM KELUARGA HARAPAN (PKH) DI KECAMATAN JEKAN RAYA KOTA PALANGKA RAYA
}

\author{
Implementation of Program policy of Family Harapan (PKH) in Jekan Raya Sub-district \\ of Palangka Raya City
}

\author{
Muhammad Riban Satia* \\ Suhardi
}

Universitas Muhammadiyah Palangkaraya, Palangka Raya, Central Kalimantan, Indonesia

email: $\underline{\text { dr.ribansatia@gmail.com }}$

\begin{abstract}
Abstrak
Dalam implementasi Program Keluarga Harapan ada beberapa hal yang perlu diperhatikan mulai dari bagaimana tahapannya, kemampuan pelaksananya, komunikasi yang terbangun, kesesuaian pelaksanaan dengan pedoman yang ada, serta komitmen peserta PKH terkait kewajibannya.
\end{abstract}

Berdasarkan hasil penelitian yang telah dilakukan, maka dapat ditarik kesimpulan, yaitu: Bahwa proses implementasi Program Keluarga Harapan di kecamatan Jekan Raya dilakukan melalui beberapa tahap, yaitu dimulai dari pemilihan dan penetapan peserta $\mathrm{PKH}$, adanya pertemuan awal, tahap pembayaran, adanya pembentukan kelompok lbu penerima PKH, Verifikasi Komitmen, penangguhan dan pembatalan, serta proses pengaduan. Secara umum implementasi Program keluarga Harapan (PKH) di Kecamatan Jekan Raya sudah berjalan dengan baik dan lancar. Dimana proses setiap tahapan pelaksanaan program ini sudah berjalan dengan semestinya karena dilakukan dengan mengacu pada prosedur dan mekanisme yang ada dalam ketentuan PKH. Keberhasilan implementasi PKH di kecamatan Jekan Raya juga tidak terlepas dari peran implementornya, komunikasi yang terbangun, karakteristik agen pelaksana serta juga dari peserta PKH itu sendiri di dalam komitmennya melaksanakan kewajibannya.

Beberapa kendala atau hambatan yang terjadi dalam proses Implementasi Program Keluarga Harapan (PKH) di kecamatan Jekan Raya yaitu menyangkut masalah ketidak pastian jadwal tanggal pembayaran, serta juga adanya respon sinis atau kecemburuan sosial masyarakat non peserta $\mathrm{PKH}$ terhadap masyarakat peserta PKH.
Accepted

January 2019

Published

April 2019

\begin{abstract}
In the implementation of the Harapan family Program, Several things need to be considered, ranging from how to the stages, the implementation capability, communication that awakened, conformity of implementation with existing guidelines, and the commitment of participants of PKH related lts obligations.

Based on the results of the research that has been done, it can be concluded, namely: that the process of implementing the Program family hope in Jekan Raya Sub-district is done through several stages, namely starting from the selection and establishment of PKH participants, The initial meeting, the payment phase, the establishment of a group mother of PKH recipients, verification of commitments, suspension and cancellation, and complaints process. In general, the implementation of the Program family Harapan $(P K H)$ in Jekan Raya subdistrict has been running well and smoothly. Where the process of each stage of implementation of this program has been run properly because it is done by referring to the procedures and mechanisms in the provisions of $\mathrm{PKH}$. The success of PKH implementation in Jekan Raya sub-district is also not separated from its implementation role, communication that awakened, the characteristics of implementing agents as well as from participants of PKH itself in its commitment to carry out its obligations.
\end{abstract}

Some obstacles or obstacles that occurred in the process of implementation of family Harapan Program (PKH) in Jekan Raya Sub-district is concerned with the problem of uncertainty payment date, as well as a cynical response or social jealousy of the community Participants of the PKH community.

\section{PENDAHULUAN}

Permasalahan penting yang dihadapi bangsa

Indonesia adalah kemiskinan. Sejak zaman kemerdekaan bangsa Indonesia sudah dihadapkan dengan permasalahan kemiskinan dan sampai sekarang tetap menjadi masalah utama bangsa Indonesia. 
Masalah kemiskinan sangat kompleks dan bersifat multidimensional, karena berkaitan dengan aspek sosial, ekonomi, budaya dan aspek lainnya (Edi Suharto, 2009).

Program Keluarga Harapan adalah suatu program yang memberikan bantuan tunai kepada Rumah Tangga Sangat Miskin, jika mereka memenuhi persyaratan yang terkait dengan upaya peningkatan kualitas sumberdaya manusia (SDM), yaitu pendidikan dan kesehatan. Adapun manfaat Program Keluarga Harapan secara umum adalah merubah perilaku keluarga sangat miskin untuk memberikan perhatian yang besar kepada pendidikan dan kesehatan anaknya. Sedangkan tujuan utama dari Program Keluarga Harapan adalah untuk mengurangi kemiskinan dan meningkatkan kualitas sumberdaya manusia terutama pada kelompok masyarakat miskin. Tujuan tersebut sekaligus sebagai upaya mempercepat pencapaian target.

Berdasarkan data Badan Pusat Statistik, tahun 2017 menunjukan terjadi pengurangan angka kemiskinan, menjadi 10,12 persen. Pemerintah ingin ada peningkatan pada akhir periode pertama jabatan Presiden Jokowi, turun menjadi sekitar 9 persen, angka kemiskinan turun I persen lebih.

Data Kementerian Sosial tahu 2017 menunjukan bahwa jumlah penerima manfaat Program Keluarga Harapan saat ini tercatat sekitar 10 juta keluarga atau sekitar 40 juta jiwa. Jumlah tersebut lebih banyak dari angka kemiskinan di Indonesia 26,5 juta jiwa. Sebagai salah satu cara mencapai target penurunan angka kemiskinan, Pemerintah akan mengoptimalkan peran para pendamping Program Keluarga Harapan di daerah.

\section{Lahirnya Program Keluarga Harapan di} Indonesia dilatar belakangi oleh keterbatasan keluarga sangat miskin dalam mengakses pelayanan kesehatan. Kenyataan ini terlihat dari angka kematian bayi pada kelompok penduduk berpendapatan terendah pada tahun 2003-2007 adalah 56 per 1000 kelahiran hidup, sedangkan pada kelompok berpendapatan tertinggi tinggal 26 per 1000 kelahiran hidup (Edi Suharto, 2009). Angka kematian ibu di Indonesia juga tinggi, yaitu sekitar 228 wanita per 100 ribu kelahiran hidup atau tertinggi di Asia Tenggara (Edi Suharto, 2009). Penyebab tingginya angka kematian ibu antara lain adalah tidak adanya kehadiran tenaga medis pada saat kelahiran, fasilitas kesehatan yang kurang memadai, bahkan tidak tersedia pada saat dibutuhkan tindakan, atau masih banyaknya rumah tangga miskin yang lebih memilih tenaga kesehatan tradisional daripada tenaga medis lainnya.

Kenyataan lain yang juga melatarbelakangi peluncuran Program Keluarga Harapan yaitu keterbatasan masyarakat miskin untuk mengakses layanan pendidikan. Sebagian dari anak-anak keluarga sangat miskin ada yang sama sekali tidak dapat mengenyam bangku sekolah karena harus mencari nafkah. Selain itu, meskipun angka partisipasi sekolah dasar tinggi, masih banyak anak keluarga miskin yang putus sekolah atau tidak melanjutkan ke SMP/MTs. Kondisi ini membuat kualitas generasi penerus keluarga miskin senantiasa rendah dan akhirnya terperangkap dalam lingkaran kemiskinan. Alasan rumah tangga sangat miskin untuk tidak melanjutkan sekolah disebabkan oleh tidak adanya biaya, bekerja untuk mencari nafkah, merasa pendidikannya sudah cukup, dan alasan lainnya.

\section{METODOLOGI}

Dalam penelitian ini penulis menggunakan metode penelitian deskriptif dengan pendekatan kualitatif, Peneliti hanya mengembangkan konsep dan menghimpun fakta tetapi tidak melakukan pengujian hipotesis. Oleh sebab itu penelitian ini terbatas pada usaha mengungkapkan suatu keadaan atau peristiwa subjek atau objek penelitian pada saat sekarang berdasarkan fakta yang tampak atau sebagaimana 
adanya (fact finding), dalam penelitian ini akan berupaya memberikan gambaran yang jelas mengenai fakta yang terjadi dalam Program Keluarga Harapan di Kecamatan Jekan Raya Kota Palangka Raya.

\section{HASIL DAN PEMBAHASAN}

Dari seluruh data yang telah disediakan secara menyeluruh yang diperoleh selama penelitian terhadap fenomena-fenomena yang ada kaitannya dengan Pelaksanaan Program Keluarga Harapan di Kecamatan Jekan Raya, maka dilakukan analisa terhadap setiap data yang ada dan fakta yang didapat berdasarkan data lapangan penelitian melalui analisa data dan penguraian masalah-masalah yang terjadi.

Kelembagaan pelaksanaan Program Keluarga Harapan di Kecamatan Jekan Raya terdiri dari UPPKH Pusat, UPPKH Kota/Kota dan UPPKH Kecamatan Jekan Raya (selaku pendamping kecamatan). Tim Pengendali di Pusat, Tim Pengarah dan Tim Teknis Pusat, serta Tim Koordinasi Program Keluarga Harapan Provinsi dan Kab/Kota fungsinya untuk membantu kelancaran program serta PT Pos yang bertugas menyampaikan informasi berupa undangan pertemuan, perubahan data, pengaduan dan seterusnya serta menyampaikan bantuan ke KSM.

Kelembagaan organisasi tersebut di atas menyediakan peta sederhana untuk menunjukkan interaksi formal yang diterapkan. Hal ini sejalan dengan pendapat Edward III yang menyatakan bahwa Struktur Birokrasi merupakan salah satu faktor yang mempengaruhi keberhasilan impelemntasi sebuah kebijakan. Dalam implementasi kebijakan, struktur organisasi mempunyai peranan yang penting. Salah satu dari aspek struktur organisasi adalah adanya prosedur operasi yang standar (standard operating procedures/ SOP). Fungsi dari SOP menjadi pedoman bagi setiap implementor dalam bertindak. Struktur organisasi yang terlalu panjang akan cenderung melemahkan pengawasan dan menimbulkan red-tape, yakni birokrasi yang rumit dan kompleks. Hal demikian pada gilirannya menyebabkan aktivitas organisasi tidak fleksibel.

Kebijakan Program Keluarga Harapan di Kecamatan Jekan Raya menunjukan bahwa program ini telah dilaksanakan berdasarkan standar mekanisme dan prosedur, kesesuaian jumlah bantuan, manfaat dana bagi peserta Program Keluarga Harapan dan waktu pembagian dana. Mekanisme dan prosedur, kesesuaian jumlah bantuan yang diterima oleh peserta telah berjalan dengan baik dan sesuai dengan pedoman umum pelaksanaan Program Keluarga Harapan, begitu juga dengan manfaat dana Program Keluarga Harapan yang sudah meringankan beban peserta Program Keluarga Harapan baik dibidang pendidikan maupun dibidang kesehatan. Namun terkait waktu pembayaran bantuan Program Keluarga Harapan di Kecamatan Jekan Raya belum tepat pada waktu yang telah ditentukan. Sedangkan terkait ketepatan sasaran kebijakan, ditemukan bahwa proses pemilihan dan penetapan peserta Program Keluarga Harapan di Kecamatan Jekan Raya telah tepat sasaran walaupun dalam prosedur akhir yaitu validasi data dilakukan lebih awal yang seharusnya dilakukan pada pertemuan awal. Hal ini dilakukan untuk memperoleh ketepatan sasaran Rumah Tangga Sangat Miskin yang benar-benar memenuhi kriteria Program Keluarga Harapan. Temuan di atas cukup menggembirakan dari sisi adanya konsistensi yang diberikan dalam pelaksanaan kebijakan. Jika yang dikomunikasikan berubah-ubah akan membingungkan dalam pelaksanaan kebijakan yang bersangkutan.

Sesuai regulasi pelaksana Program Keluarga Harapan di Kecamatan Jekan Raya dikoordinir oleh pendamping Program Keluarga Harapan yang bertanggung jawab terhadap pelaksanaan Program Keluarga Harapan di kecamatan Jekan Raya. Tenaga pendamping Program Keluarga Harapan dipersyaratkan berusia sekurang-kurangnya 21 tahun, pendidikan minimal SLTA atau sederajat, diutamakan bertempat tinggal di kecamatan/ Kabupaten yang bersangkutan, 
memiliki pemahaman dibidang kesehatan dan pendidikan, serta mempunyai kemampuan mengoperasikan komputer.

Pendamping Program Keluarga Harapan di Kecamatan Jekan Raya saat ini berjumlah 4 (empat) orang adalah lulusan Sarjana S-I yang berdomisili dan bertempat tinggal diwilayah Kecamatan Jekan Raya. Jumlah pendamping ini cukup menjamin bahwa dari sisi sumber daya implementasi Program Keluarga Harapan dapat terlaksana dengan baik. Hal ini sejalan dengan dengan teori Edward bahwa implementasi kebijakan yang baik harus ditunjang oleh sumberdaya baik sumberdaya manusia, materi dan metoda. Sasaran, tujuan dan isi kebijakan walaupun sudah dikomunikasikan secara jelas dan konsisten, tetapi apabila implementor kekurangan sumberdaya untuk melaksanakan, implementasi tidak akan berjalan efektif dan efisien. Tanpa sumberdaya, kebijakan hanya tinggal di kertas menjadi dokumen saja tidak diwujudkan untuk memberikan pemecahan masalah yang ada di masyarakat dan upaya memberikan pelayan pada masyarakat.

Komunikasi antar organisasi atau lembaga terkait dalam menyukseskan pelaksanaan kegiatan Program Keluarga Harapan di Kecamatan Jekan Raya sudah berjalan dengan baik, masing-masing pihak atau pemangku kepentingan selalu berkoordinasi, seperti dari puskesmas selalu menyampaikan data ibu hamil dan anak balita yang selalu memeriksakan kesehatannya dan dari UPT Dinas Pendidikan Kecamatan juga selalu memberikan informasi dan data-data peserta didik Program Keluarga Harapan. Pada setiap kegiatan rapat koordinasi tingkat kecamatan selalu dibahas hal-hal yang bersifat kendala yang dihadapi oleh pendamping Program Keluarga Harapan di kecamatan dalam melakukan tugas dan fungsinya. Masing-masing pihak pelaksana menjalankan tugas sesuai dengan wewenang dan pihak pelaksana juga melaksanakan tugasnya dengan baik.
Para peserta Program Keluarga Harapan di Kecamatan Jekan Raya telah patuh dan taat dalam melaksanakan kewajiban mereka itu dapat dilihat dari segi baik itu komponen kesehatan maupun pendidikan. Bagi peserta yang memiliki balita, mereka telah membawa ke posyandu dan sedangkan bagi peserta yang usia SD dan SMP telah hadir ke sekolah dengan jumlah kehadiran yang tidak melanggar ketentuan Program Keluarga Harapan.

Dukungan dari komponen masyarakat, seperti tokoh ulama melalui dakwahnya selalu menghimbau warganya untuk selalu memperhatikan masalah yang berhubungan dengan kesehatan dan pendidikan, itu sangat sejalan dengan konsep dasar Program Keluarga Harapan.

Berdasarkan pembahasan tersebut di atas, maka dapat dikatakan implementasi Program Keluarga Harapan di Kecamatan Jekan Raya, berdasarkan variabel ; I. Kelembagaan Program Keluarga Harapan (PKH), 2. Standar dan Sasaran Program, 3. Sumber Daya, 4. Komunikasi dan Hubungan Antar Organisasi, 5. Karakteristik Agen Pelaksana dan 6. Komitmen peserta Program Keluarga Harapan terhadap kewajibannya, secara umum sudah berjalan dengan baik.

Faktor Pendukung dan Penghambat Dalam Pelaksanaan Program Keluarga Harapan (PKH) di Kecamatan Jekan Raya

Pelaksanaan Program Keluarga Harapan tidak terlepas dari adanya faktor pendukung. Dalam penelitian ini factor pendukung program ini yaitu adanya komitmen yang kuat antara pemerintah pusat dan daerah untuk mensukseskan Program Keluarga Harapan guna mensejahterakan masyarakat Rumah Tangga Sangat Miskin.

Faktor pendukung lainnya yaitu adanya koordinasi yang baik dari aktor yang terlibat. Aktor tersebut meliputi perangkat kecamatan, di bidang pendidikan yaitu guru/wali kelas yang harus melakukan absensi rutin agar partisipasi siswa dalam kegiatan 
belajar mengajar dapat terpantau, sedangkan di bidang kesehatan yaitu bidan desa yang berada di lokasi peserta Program Keluarga Harapan menetap. Perwakilan bidan harus selalu memantau perkembangan kondisi kesehatan dan gizi dari ibu hamil, ibu nifas, dan balita ketika melakukan kegiatan posyandu. Dengan adanya partisipasi dari pihak-pihak terkait maka program ini dapat berjalan dengan baik.karena itu dukungan dari berbagai aktor inilah yang diharapkan nantinya akan lebih mampu meningkatkan kualitas hidup Rumah Tangga Sangat Miskin.

Selain itu, faktor pendukung pelaksanaan program adalah dukungan finansial yang mencukupi sehingga dapat menentukan kesuksesan tujuan. Dalam pelaksanaan Program Keluarga Harapan, proses pembayaran atau pendanaan merupakan hal terpenting sebagai penentu keberhasilan. Disamping itu pendanaan menjadi hal penting sehingga diperlukan pengelolaan maupun pengawasan yang baik agar dalam pendanaannya sesuai dengan ketentuan. Olehkarena itu dengan anggaran yang cukup, pelaksanaan program keluarga harapan ini dapat berjalan dengan baik dan pada akhirnya kualitas hidup Rumah Tangga Sangat Miskin sebagai tujuan program dapat meningkat.

Sedangkan dari hasil penelitian diketahui bahwa bahwa faktor penghambat merupakan sebuah acuan bagi pelaksanaan program sebagai hasil evaluasi. Adapun yang menjadi faktor penghambat dalam proses Implementasi Program Keluarga Harapan di kecamatan Jekan Raya yaitu menyangkut masalah ketidak pastian jadwal tanggal pembayaran akan dilakukan, tenaga pendamping Program Keluarga Harapan agar dalam pelaksanaan dapat lebih maksimal lagi, serta juga adanya respon sinis atau kecemburuan sosial masyarakat non peserta Program Keluarga Harapan terhadap masyarakat peserta Program Keluarga Harapan.

\section{KESIMPULAN}

Bahwa implementasi Program Keluarga Harapan di Kecamatan Jekan Raya sesuai vaiabel; Kelembagaan Program Keluarga Harapan (PKH), Standar dan Sasaran Program, Sumber Daya, Komunikasi dan Hubungan Antar Organisasi, Karakteristik Agen Pelaksana, serta Komitmen peserta program terhadap kewajibannya, secara umum sudah berjalan dengan baik.

Faktor-faktor yang mempengaruhi implementasi Pogram keluarga Harapan di Kecamatan Jekan Raya adalah :

a. Faktor Pendukung

I) Komitmen yang kuat antara pemerintah pusat dan daerah untuk mensukseskan Program Keluarga Harapan guna mensejahterakan masyarakat Rumah Tangga Sangat Miskin.

2) Koordinasi yang baik dari aktor yang terlibat, meliputi perangkat kecamatan di bidang, kesehatan dan pihak-pihak instansi terkait lainnya.

3) Dukungan finansial dari pemerintah yang mencukupi sehingga dapat menentukan kesuksesan tujuan.

b. Faktor yang menghambat

I) Ketidak pastian jadwal tanggal pembayaran dilakukan,

2) Tenaga pendamping diharapkan lebih maksimal, dan

3) Adanya respon sinis atau kecemburuan sosial masyarakat non peserta Program Keluarga Harapan terhadap masyarakat peserta Program Keluarga Harapan. 


\section{REFERENSI}

Anonim. 2014. Study on Conditional cash transfers and their impact on children Final Report, Volume II: Case Studies. European Union, European Commission B-1049 Brussels.

Centofanti, Shelby L, 2015. The Importance Of Domestic Buy-In In Globalizing Social Policy: Origins Analysis of Conditional Cash Transfers in Latin American. The Watson Institute for International Studies, Thayer St, Providence, RI, USA

Effendi, Onong Uchjana. 200I. IImu Komunikasi, Teori dan Praktek. Remaja Rosdakarya. Bandung.

Edi Suharto. 2009. Membangun Masyarakat Memberdayakan Rakyat, Kajian Strategis Pembangunan Kesejahteraan social dan Pekerjaan Sosial. Bandung: PT Rafika Aditama.

Husein Umar. 2008. Metode Riset Bisnis. PT. Gramedia Pustaka Utama. Jakarta.

Leo Agustino 2006. Dasar-dasar Kebijakan Publik. Alfabeta .Bandung.

Masunzu, Daniel Salvatory. 2014. Conditional cash transfers (CCTs) and Poverty Alleviation: A comparative study between Jamaica and Tanzania. Oslo and Akershus University College, Faculty of Social Science, Oslo.

Nugroho. 2004. Pemrograman Berorientasi Objek. Informatika .Bandung.

Panggabean. 20II. Dampak dana bergulir bagi koperasi dan UKM.

Perpres No. 15 Tahun 2010 Tentang Percepatan Penanggulangan Kemiskinan.

Susiana. 2010. Pelaksanaan Program Bantuan Dana Bergulir Terhadap Kelompok Swadaya Masyarakat BKM.

Undang-Undang No. 40 Tahun 2004 Tentang Sistem Jaminan Sosial Nasional. 